\title{
Effect of the Initial Precipitation States on the Creep and Creep \\ Rupture Characteristics of 18-8-Ti Stainless Steel*
}

\author{
By Teruo YUKITOSHI**
}

\begin{abstract}
Synopsis
The initial precipitation states in 18-8-Ti stainless steel were varied by heat treatment to contain precipitates of various shapes to various amounts and their effects on the creep and creep rupture characteristics investigated. Hardness at room temperature and short time tensile properties at high temperature were examined in comparison with creep strength. The microstructures from extracted replica and thin foil were observed by electron microscopy.

The creep characteristics were well correlated to soluble $\mathrm{Ti}$ (or soluble $\mathrm{C}$ ) content, and it was suggested that the mutual action between soluble $\mathrm{Ti}$ and C is fairly great for creep strength. Moreover, the creep characteristics were strongly influenced by the initial precipitation states; this was discussed from the viewpoint of mutual action between precipitates and dislocation. The needle type precipitate, which was most probably $\mathrm{Cr}_{3} \mathrm{C}_{2}$, was found to be responsible for the great decrease of creep strength, and its mechanism was discussed. It was observed that the effect of the initial precipitate state on the hardness and short time tensile properties is very small.
\end{abstract}

\section{Introduction}

Many theoretical treatments of creep and creep rupture phenomena have hitherto been reported. In the early days, the rate process theory was dominant, but with the development of dislocation theory, it has been taken over by the latter.

Most of those creep theories deal with pure metal or solid solution alloy that has no precipitate. There are only Mclean's experiment, ${ }^{11}$ which handles the relation between the mean free pass of precipitates and the creep rate, and Ansell's theory, ${ }^{2)}$ which discusses the effect of the precipitates on the creep strength; none of them, however, is as yet capable of fully explaining the creep characteristics of any material. Therefore, it is on the experimental results in the transmission electron microscopy that new theories for creep deformation are expected to grow.

On the other hand, as commercial steels generally contain precipitates of many kinds of shapes, e.g. granular, thread, needle, plate, etc., theoretical treatment of precipitates is very difficult. Specifically, because the boiler tube steels, of which the steel of this report is one, are to serve at high temperature for a long time, the precipitates such as carbide, nitride, and intermetallic compounds always coexist in various shapes. Therefore, it is necessary and very important that the effect of precipitates on the characteristics of a steel, especially characteristics at high temperatures, be investigated, even if only qualitatively. From these viewpoints, 18-8-Ti steel (SUS 29TB), which is very popular for boiler tube in Japan, was chosen as a test material, and the effect of precipitate state on the creep characteristics was examined.

Although the metallurgical structures and high temperature strength of 18-8-Ti steel have already been often investigated, there are a few reports on the role of individual precipitates. For example, in the course of an investigation for the effect of heat-treatment on the high temperature strength of $18-8-\mathrm{Ti}^{3}{ }^{3)}$ it was indicated that the creep characteristics depend on the metallurgical changes that occur during creep deformation, and that the appearance of needle precipitate (most probably $\mathrm{Cr}_{3} \mathrm{C}_{2}$ ) is phenomenologically related to the large decrease of creep strength. In that case, the specimen was aged at $750^{\circ} \mathrm{C}$ to accelerate the precipitation. It was subsequently observed ${ }^{4), 5)}$ that these needle precipitates also appear after a long time creep testing at $650^{\circ}$ and $700^{\circ} \mathrm{C}$. Moreover, it was definitely shown that the $\mathrm{Cr}_{3} \mathrm{C}_{2}$ needles precipitate not only on TiC as nucleus, but also spontaneously in the grain, and that the precipitation of $\mathrm{Cr}_{3} \mathrm{C}_{2}$ coincides with the strength decrease in the stress-rupture time curve. It was thought then that these needle precipitates play a great role in the large decrease of creep rupture strength.

In this report, the state of precipitation, i.e. the shape and amount, was varied by changing the heat treatment and the effect of these initial states of precipitation on the creep characteristics was investigated. Few 18-8$\mathrm{Ti}$ steels with extra low carbon content were tested to define the no-precipitation state. Also, room temperature hardness and high temperature tensile properties were examined with regard to the initial precipitation state.

\section{Specimen and Examination Method}

The 18-8-Ti steel that was selected as test material

Table 1. Chemical composition (\%)

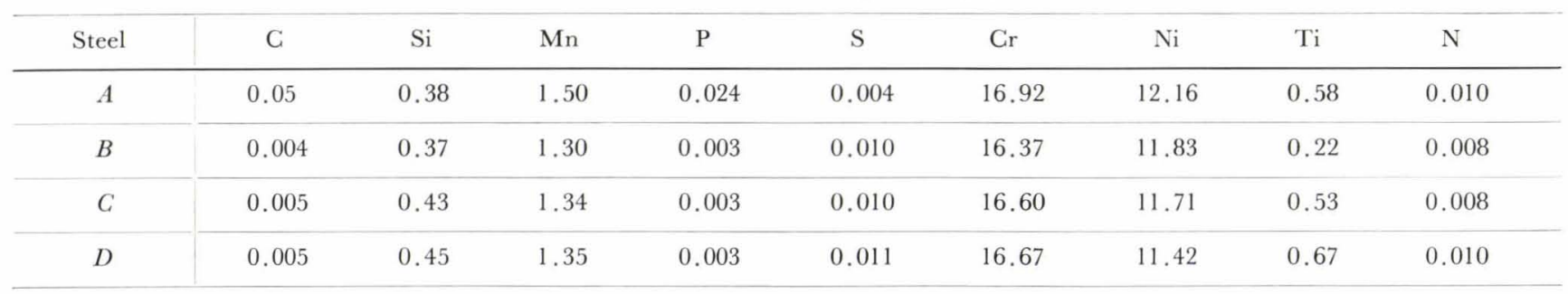

* Received September 30, 1968.

** Gentral Research Laboratories, Sumitomo Metal Industries, Ltd., Nishinagasu-Hondori, Amagasaki 660. 
(Steel $A$ ) was so manufactured in a $50 \mathrm{t}$ electric furnace that the $\mathrm{Ti}$ content was a little more $(\mathrm{Ti} / \mathrm{C}=12)$ than JIS specification $\left(\mathrm{Ti}^{\circ} \%=\mathrm{C} \% \times 5\right.$ to $\left.0.60 \%\right)$; it was to avoid the precipitation of $\mathrm{M}_{23} \mathrm{G}_{6}$. The steel was rolled, forged to $20 \mathrm{~mm} \phi$, and then heat treated. The extra low carbon 18-8-Ti steels $(B, C$, and $D)$ were prepared in a $3 \mathrm{~kg}$ vacuum furnace from electrolytic iron. Table 1 shows the chemical composition of steels.

All specimens were first solution treated at $1300^{\circ} \mathrm{C}$ to obtain as much a same grain size and solid solution state as possible: the grain size was between Nos. 1.5 and 1.8. Aging treatment was so selected from earlier investigation results as to obtain differently shaped precipitates (thread, granular, needle) that are typical for 18-8-Ti steels. ${ }^{4)-6)}$ The heat treatment of steel $A$ is shown in Table 2. Steels $B, C$, and $D$ were only solution treated by the method (1) in Table 2 .

The residue from specimen was extracted with 1: 1 hydrochloric acid and chemically analyzed. The creep and creep rupture characteristics were measured at $650^{\circ} \mathrm{C}$ with $14.0 \mathrm{~kg} / \mathrm{mm}^{2}$ stress. In this testing, preheating time was kept as short as possible to avoid the precipitation during heating. The test piece dimensions were $10 \phi \times 50 \mathrm{~mm}$ G. L. with projections. The metallurgical structures in the initial states were observed by the extraction replica method in an electron microscope. Metallography was conducted at three levels of deformation: one at the conclusion and the other two at midway of creep rupture test. In the latter, the test was interrupted by pulling up the heating furnace, leaving the test load intact, after 3 or $100 \mathrm{hr}$ of creep deformation. In either case, $1 \mathrm{~mm}$ thick sample was cut from the middle of the tested specimen along its axis, polished first chemically in a solution (fluoric acid: hydrochloric acid: hydrogen peroxide $=1: 1: 2$ ) then electrolytically in chromic acid phosphoric acid mixture. The thin foil prepared in this way was satisfactory for the transmission electron microscopy. As the contribution of grain boundary sliding to the creep strength is known to be small under low stresses, ${ }^{7)}$ attention was directed mainly to the precipitates that are in the grain. The big precipitates, such as the nonmetallic inclusions, were neglected in the structure observation, for they can offer little effect on the high temperature strength.

\section{Experimental Results}

\section{Initial Precipitation State}

The initial states of precipitation of heat treated specimens are illustrated in Photo. 1. Photograph 2 shows the magnified view of typical precipitates in specimen $A$. The results of chemical and X-ray analysis of extracted residue are shown in Table 3. As solution treated at $1300^{\circ} \mathrm{C}$, few precipitates were seen in the electron micrographs of steels $A$ to $D$. However, big inclusions were sometimes found in the electron micrographs; these were considered to be $\mathrm{Ti}_{2} \mathrm{~S}$ and $\mathrm{TiN}$, which are insoluble by the solution treatment.

The thread precipitates were identified to be TiC; most of them were composed of many fine granular precipitates linked together as seen in Photo. 2. In the
Table 2. Heat treatment

\begin{tabular}{c|c}
\hline Mark & Heat treatment \\
\hline 1 & $1300^{\circ} \mathrm{C} \times 1 \mathrm{hr}$ W.Q. \\
\hline 2 & $1300^{\circ} \mathrm{C} \times 1 \mathrm{hr}$ W.Q. $+750^{\circ} \mathrm{C} \times 2 \mathrm{hr}$ W.Q. \\
\hline 3 & $1300^{\circ} \mathrm{C} \times 1 \mathrm{hr}$ W.Q. $+800^{\circ} \mathrm{C} \times 2 \mathrm{hr}$ W.Q. \\
\hline 4 & $1300^{\circ} \mathrm{C} \times 1 \mathrm{hr}$ W.Q. $+850^{\circ} \mathrm{C} \times 20 \mathrm{hr}$ W.Q. \\
\hline 5 & $1300^{\circ} \mathrm{C} \times 1 \mathrm{hr}$ W.Q. $+900^{\circ} \mathrm{C} \times 10 \mathrm{~min}$ W.Q. \\
\hline 6 & $1300^{\circ} \mathrm{C} \times 1 \mathrm{hr}$ W.Q. $+950^{\circ} \mathrm{C} \times 20 \mathrm{hr}$ W.Q. \\
\hline 7 & $1300^{\circ} \mathrm{C} \times 1 \mathrm{hr}$ W.Q. $+1000^{\circ} \mathrm{C} \times 2 \mathrm{hr}$ W.Q. \\
\hline 8 & $1300^{\circ} \mathrm{C} \times 1 \mathrm{hr}$ W.Q. $+1100^{\circ} \mathrm{C} \times 2 \mathrm{hr}$ W.Q. \\
\hline
\end{tabular}
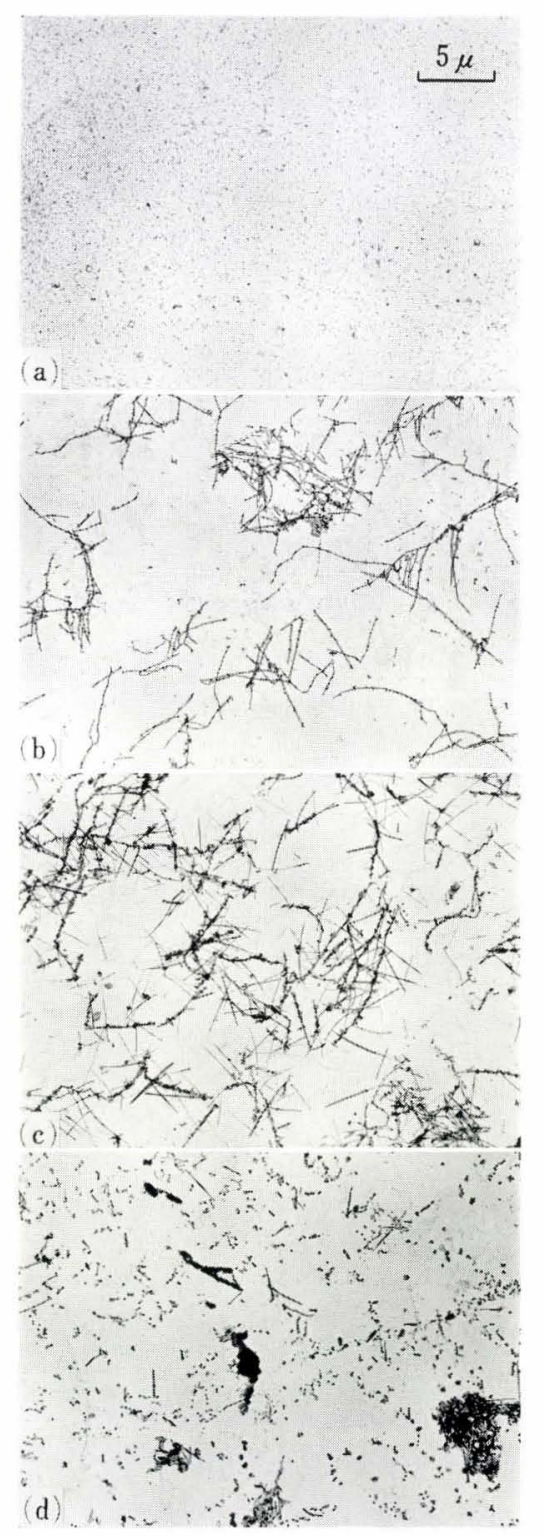

Photo. 1. Initial states of precipitation in steel $A$. Different states were realized by changing heat treatment as indicated.
(a) $1300^{\circ} \mathrm{C} \times 1 \mathrm{hr}$ W.Q.
(b) $1300^{\circ} \mathrm{C} \times 1 \mathrm{hr}$ W.Q. $+800^{\circ} \mathrm{C} \times 2 \mathrm{hr}$ W.Q.
(c) $1300^{\circ} \mathrm{C} \times 1 \mathrm{hr}$ W.Q. $+850^{\circ} \mathrm{C} \times 20 \mathrm{hr}$ W.Q.
(d) $1300^{\circ} \mathrm{C} \times 1 \mathrm{hr}$ W.Q. $+1000^{\circ} \mathrm{C} \times 2 \mathrm{hr}$ W.Q. 
aged specimens of methods (2), (3), and (4), the higher the aging temperature, the greater became the precipitation content and the larger grew the individual granular precipitates. As the aging temperature increases further, the part linking the granular precipitates disappeared, and the precipitation content of Ti de-

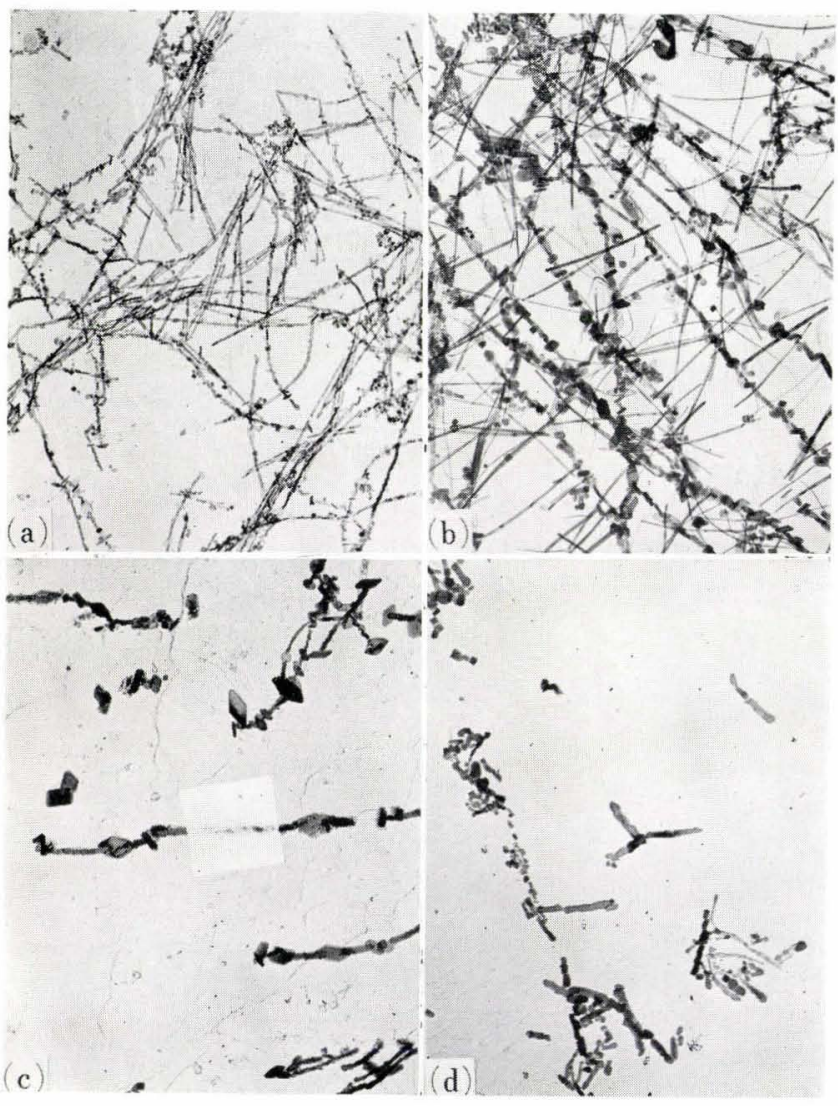

Photo. 2. Electron micrographs of typical precipitates in 18 8-Ti stainless steel. The white square in (c) is where the limited field electron diffraction was taken. $(\times 20000)(4 / 5)$

(a) Thread precipitate

(b) Needle and thread precipitate

(c) Granular and thread precipitate

(d) Granular precipitate creased. Finally the connected precipitates were separated, and grew into the so-called "granular" precipitates. In the specimen aged at yet higher temperature of method (8), the precipitates did not grow to a thread shape but remained as a slightly elongated granular. These were also identified as TiC.

In the aged specimens of methods (4) and (6), on the other hand, very fine, long, and moderately curved needle precipitates were observed together with thread precipitates. Some of them seem to have precipitated from $\mathrm{TiC}$ as nucleus, but most spontaneously and independently in the grain. As the needle precipitates they were definitely distinguishable from thread precipitates. Although Debye rings of their electron diffraction pattern corresponded well to those of $\mathrm{Cr}_{3} \mathrm{C}_{2}$ according to the ASTM powder diffraction file, the indices of the Laue pattern did not always agree with those of $\mathrm{Cr}_{3} \mathrm{C}_{2}$ (Photo. 3). Furthermore, when the residue from aged specimen was extracted with a $\mathrm{Br}$ alcohol solution, which was used for the extraction replica, and after the needle precipitate was confirmed to be in the residue, X-ray diffraction was taken of the residue, diffraction lines that were of the needle precipitates themselves were not recognized. This may simply mean, however, that the needle precipitates were quantitatively very small comparing with the coexisting TiC.

The chemical and X-ray analysis of the extracted residue led to the following conclusions :

(1) $\mathrm{Fe}, \mathrm{S}$, and $\mathrm{N}$ contents in residue are roughly constant in all specimens and remain within the error range of chemical analysis. As Fe content is $0.001 \%$ in all specimens, $\mathrm{Fe}$ cannot form a precipitate all by itself. Most of $\mathrm{S}$ and $\mathrm{N}$ are extracted in the residue: they are considered to have formed respectively $\mathrm{Ti}_{2} \mathrm{~S}$ and TiN or TiC(N). These precipitates have already been present in solution treated specimens, i.e. the subsequent aging treatment has nothing to do with their presence. Therefore, they may be neglected in this study.

(2) The absolute value of $\mathrm{Cr}$ content in residue increases a little during aging between $750^{\circ}$ and $950^{\circ} \mathrm{C}$

Table 3. Chemical and X-ray analysis of the residue extracted from the heat treated steels

\begin{tabular}{|c|c|c|c|c|c|c|c|c|c|c|}
\hline \multirow{2}{*}{ Mark } & \multicolumn{8}{|c|}{ Chemical analysis } & \multirow{2}{*}{$\begin{array}{l}\mathrm{X} \text {-ray } \\
\text { analysis }\end{array}$} & \multirow{2}{*}{$\begin{array}{c}\text { Shape of } \\
\text { precipitate }\end{array}$} \\
\hline & $\mathrm{Cr}$ & $\mathrm{Fe}$ & $\mathrm{N}$ & $\mathrm{S}$ & $\mathrm{Ti}$ & C & $\mathrm{C}^{*}$ & $\mathrm{C}^{* *}$ & & \\
\hline$A-1$ & 0.009 & 0.001 & 0.007 & 0.005 & 0.075 & 0.022 & 0.019 & 0.009 & TiC, $\left(\mathrm{Ti}_{2} \mathrm{~S}\right)(\mathrm{TiN})$ & - \\
\hline$A-2$ & 0.016 & 0.001 & 0.007 & 0.005 & 0.092 & 0.023 & 0.023 & 0.013 & TiC & Thread \\
\hline$A-3$ & 0.021 & 0.001 & 0.007 & 0.004 & 0.160 & 0.035 & 0.040 & 0.031 & , & Thread \\
\hline$A-4$ & 0.016 & 0.001 & 0.007 & 0.004 & 0.247 & 0.046 & 0.062 & 0.052 & , & Needle, thread \\
\hline$A-5$ & 0.010 & 0.001 & 0.007 & 0.005 & 0.230 & 0.050 & 0.058 & 0.048 & , & Thread \\
\hline$A-6$ & 0.015 & 0.001 & 0.007 & 0.005 & 0.235 & 0.040 & 0.059 & 0.049 & , & Thread, needle \\
\hline$A-7$ & 0.008 & 0.001 & 0.007 & 0.005 & 0.228 & 0.045 & 0.057 & 0.047 & , & Granular, thread \\
\hline$A-8$ & 0.010 & 0.001 & 0.007 & 0.005 & 0.155 & 0.035 & 0.039 & 0.029 & , & Granular \\
\hline
\end{tabular}

$\mathrm{C}^{*}$ : Evaluated $\mathrm{C}$ content when all of the extracted $\mathrm{Ti}$ is assumed to have precipitated as TiC.

C** : Evaluated $\mathrm{C}$ content when all of the extracted $\mathrm{S}$ and extracted $\mathrm{N}$ are in $\mathrm{Ti}_{2} \mathrm{~S}$ and $\mathrm{TiN}$ respectively, and the retained $\mathrm{Ti}$ is assumed to have precipitated as TiC. 


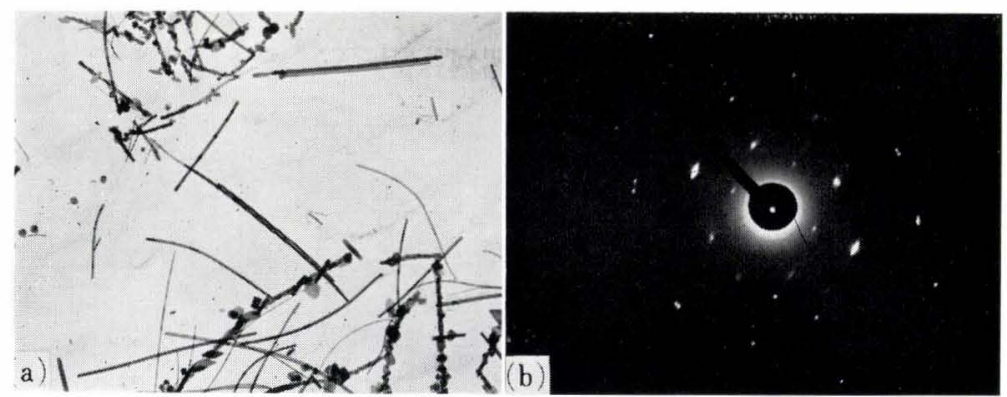

Photo. 3.

Electron micrograph and electron diffraction pattern of needle precipitate

(a) Needle precipitate $(\times 20000)\left({ }^{20} /{ }_{27}\right)$

(b) Electron diffraction pattern

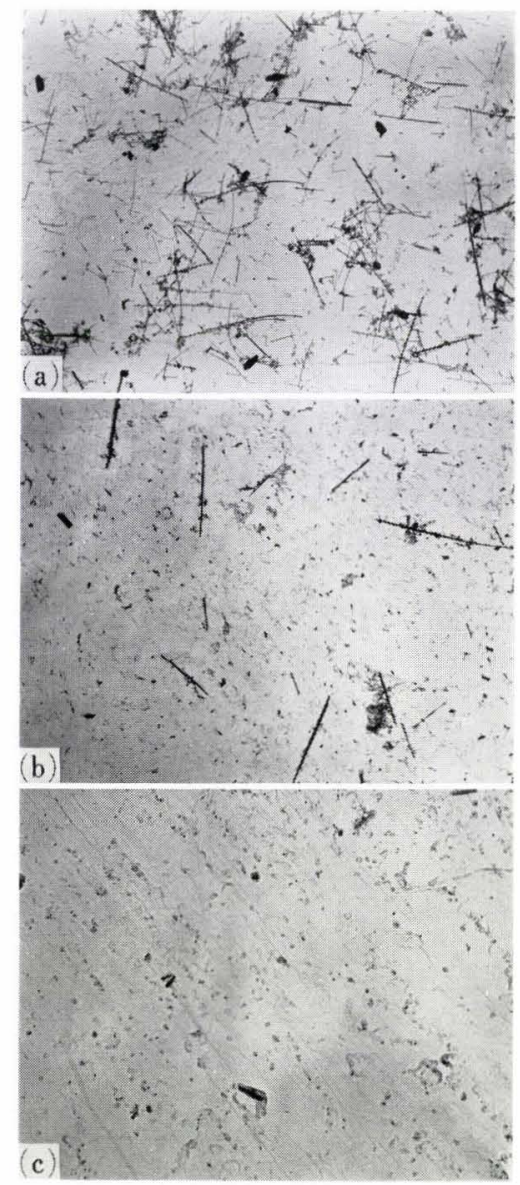

retained Ti precipitated as TiC. Because of the errors in chemical analysis for each element that accumulate in the evaluation, this line of approach will not be discussed any further in this paper.

The needle precipitates do not appear in a plain 18-8 stainless steel nor in the extra low carbon 18-8-Ti steels $B, C$, and $D$ of Table 1 , but appear only in 18-8-Ti and $18-8-\mathrm{Nb}$ steels (Photo. 4), giving same electron diffraction patterns ${ }^{5)}$ and growing from $\mathrm{TiC}$ and $\mathrm{NbC}$ as nucleus. The needle precipitate in 16-13-Mo steel looks similar, but it has been identified as $\mathrm{M}_{23} \mathrm{C}_{6} \cdot{ }^{5)}$ Though neither their composition nor precipitation process has been fully analyzed, the needle precipitate in question has apparently an intimate relationship with $\mathrm{C}, \mathrm{Ti}$, and $\mathrm{Nb}$ composition.

(5) As $\mathrm{Ti}$ content in residue can be analyzed more accurately than $\mathrm{C}$ content, all data of the following mechanical properties were arranged with respect to Ti content.

\section{Results of Creep and Creep Rupture Testing}

The creep rupture testing was conducted at $650^{\circ} \mathrm{C}$ with a stress of $14.0 \mathrm{~kg} / \mathrm{mm}^{2}$, and the effect of low stress on the high temperature strength was examined. To avoid precipitation during pre-heating, the heating time was limited to only $2 \mathrm{hr}$. The experimental results are shown in Table 4 and Fig. 1.

It was found that the creep curves depend markedly on the initial precipitation state. The creep rupture time of the aged specimens ( $A-4$ and $A-6)$ with needle precipitates was abnormally shorter than that of specimens $A-2, A-3$, and $A-5$ that had thread precipitates. Specimens with granular precipitate had intermediate creep rupture time. The characteristic values from the creep rupture curves are arranged with respect to the solution Ti content in Figs. 2, 3, and 4. The instantaneous elongation in creep rupture test generally corresponds to the elongation in the tensile test with high strain speed. In the present study, however, only the solution treated steel $A-1$ gave a great instantaneous elongation, and the others gave elongations that decreased linearly with soluble Ti content, irrespective of form and distribution of the precipitate. This tendency is similar to the results of short-time tensile testing.

On the other hand, in Figs. 3, and 4, the effect of initial state of precipitation on the creep and creep rupture strength was quite different from that on the initial elongation; it was recognized clearly not only with respect to the soluble $\mathrm{Ti}$ content, but also to the form and distribution of precipitates. The creep rupture time was almost inversely proportional to the 
Table 4. Results of creep rupture test $\left(650^{\circ} \mathrm{C}, 14.0 \mathrm{~kg} / \mathrm{mm}^{2}\right)$

\begin{tabular}{c|ccccc}
\hline $\begin{array}{c}\text { Heat } \\
\text { treatment mark }\end{array}$ & $\begin{array}{c}\text { Initial elongation } \\
(\%)\end{array}$ & $\begin{array}{c}\text { Min. creep rate } \\
(\% / 1000 \mathrm{hr})\end{array}$ & $\begin{array}{c}\text { Creep rupture } \\
\text { time } \\
(\mathrm{hr})\end{array}$ & $\begin{array}{c}\text { Elongation } \\
(\%)\end{array}$ & $\begin{array}{c}\text { Reduction of } \\
\text { area } \\
(\%)\end{array}$ \\
\hline$A-1$ & 0.9390 & 0.19 & 1016.8 & 5.0 & 0.5 \\
\hline$A-2$ & 0.5220 & 0.104 & 1490.0 & 5.0 & 10.0 \\
\hline$A-3$ & 0.3250 & 0.11 & 1192.8 & 4.0 & 14.2 \\
\hline$A-4$ & 0.1330 & 20.0 & 123.6 & 8.0 & 17.0 \\
\hline$A-5$ & 0.2240 & 0.5 & 969.5 & 5.0 & 16.9 \\
\hline$A-6$ & 0.1850 & 1.3 & 213.0 & 6.0 & 9.0 \\
\hline$A-7$ & 0.1480 & 0.4 & 462.8 & 6.0 & 11.0 \\
\hline$A-8$ & 0.3670 & 0.4 & 748.0 & 6.0 & 63.0 \\
\hline$B-1$ & 4.3060 & 180 & 117.75 & 64.0 & 77.8 \\
\hline$C-1$ & 6.5310 & 180 & 109.0 & 64.0 & 15.0 \\
\hline$D-1$ & 4.1300 & 426 & 16.75 & 6 & 22.0 \\
\hline
\end{tabular}

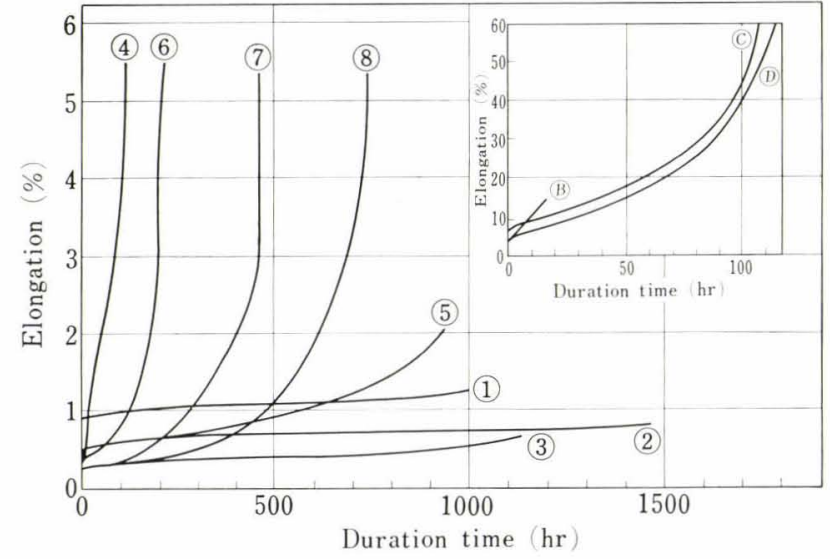

Fig. 1. Creep rupture curves at $650^{\circ} \mathrm{C}$ under $14.0 \mathrm{~kg} / \mathrm{mm}^{2}$

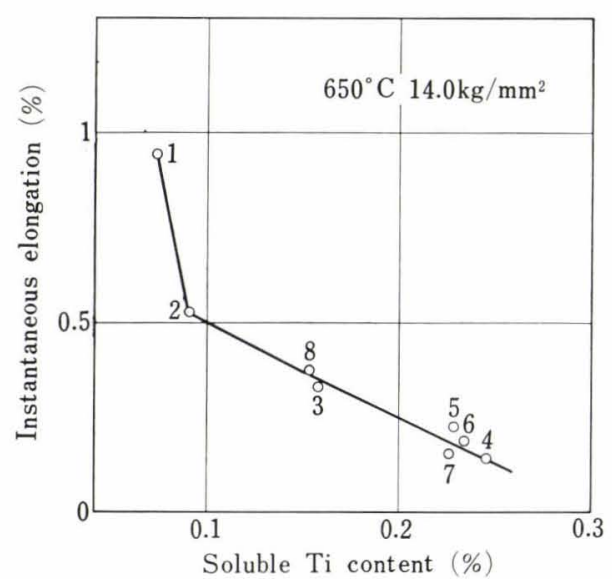

Fig. 2. Relation between instantaneous elongation and soluble Ti content

minimum creep rate, so that the creep rupture life was determined by the minimum creep rate that was obtained in a comparatively short time testing. Namely, the creep rupture strength depends greatly on the initial precipitation state. As seen in Fig. 4, the more the soluble $\mathrm{Ti}$ content, the longer becomes the creep

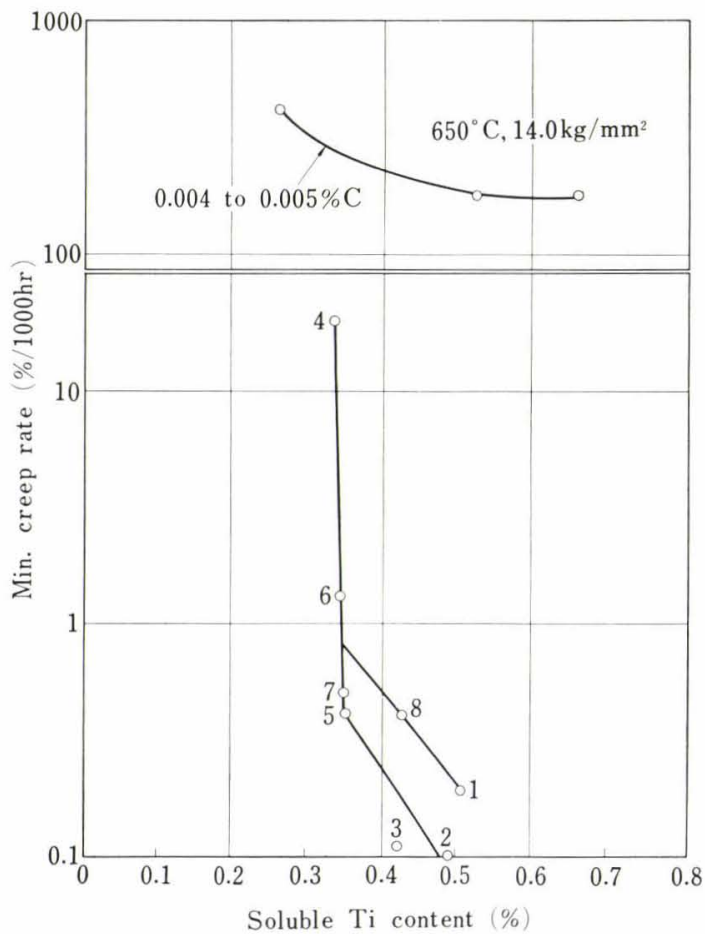

Fig. 3. Relation between min. creep rate and soluble Ti content

rupture time. However, even if the soluble Ti content is equal, the creep rupture strength was greater in the treated steels with thread precipitates $(A-2, A-3$, and $A-5)$ than that in steels with granular precipitates ( $A-7$ and $A-8$ ). Moreover, the data points as age treated 2, 3, and 5 were almost on one line, while the creep rupture time as solution treated 1 fell roughly on the extrapolated line of rupture times as treated 7 and 8. The steel as age treated 4 and 6 to contain needle precipitates had almost the same soluble $\mathrm{Ti}$ content as one treated 5 and 7 ; nevertheless, their creep rupture strengths decreased abruptly and the decrement was greater in the one as treated 4 with more needle pre- 


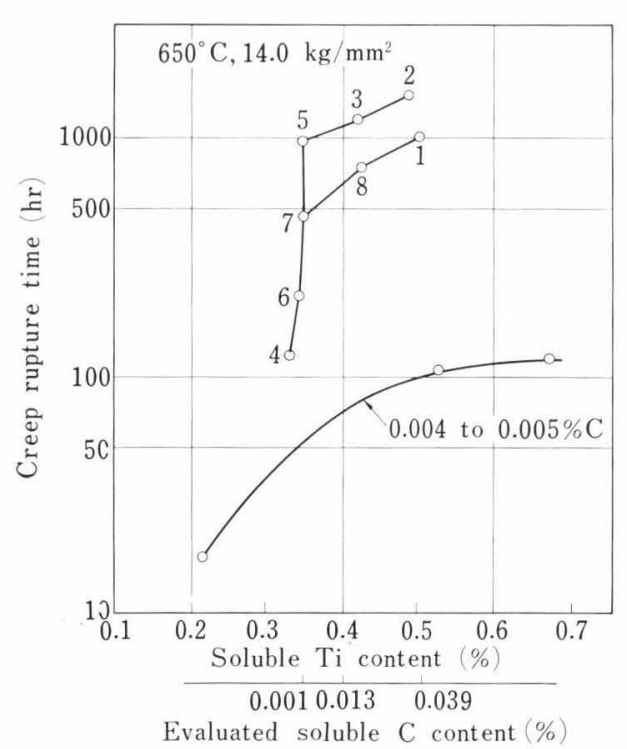

Fig. 4. Relation between creep rupture time and soluble Ti content

cipitates. On the other hand, the creep rupture strength in the extra low carbon 18-8-Ti steels seems to have increased with the soluble Ti content but saturated for more than $0.5 \%$ soluble Ti. This is considered to correspond to the real solution strengthening of $\mathrm{Ti}$, because the extra low carbon 18-8-Ti steel had no precipitates. On the other hand, the creep rupture elongation and reduction of area in steel $A$ was very small irrespective of the initial states, because all specimens tested had very large grain size. However, in the extra low carbon steels of $B, C$, and $D$, the creep rupture elongation was very large.

\section{Observation of Metallurgical Structures}

The metallurgical structures of the specimens, taken after $3 \mathrm{hr}$ and $100 \mathrm{hr}$ of creep testing at $650^{\circ} \mathrm{C}$ as well as of some other steels were directly observed by transmission electron microscopy. Typical examples of these results are shown in Photos. 5 to 8 . The solution treated steel of $A-1$ contained at first dislocations only, but after $100 \mathrm{hr}$ of creep testing characteristic banded patterns of stacking faults were recognized. The stacking fault grew considerably faster under creep than in plain heating, because the nuclei for the stacking fault growth were formed by the creep deformation. As the creep testing time increased, the stacking faults grew further and at the same time precipitates became recognizable upon them. After the completion of creep rupture test, it was seen that a part of the stacking fault had broken down and dot precipitates formed. These stacking faults were recognized in the as solution treated $A-1$ and some of specimens treated 2, that had high soluble $\mathrm{Ti}$ (or $\mathrm{C}$ ) content, but did not appear in the as treated 3 with low soluble $\mathrm{Ti}$ content. This means that the soluble $\mathrm{Ti}$ (or $\mathrm{G}$ ) content decreases the stacking fault energy. These observations agree with the generally accepted theory, in which the stacking fault is considered to have a great role for the strengthening by itself and through dispersion of carbides, which precipitate on it. ${ }^{8)}$

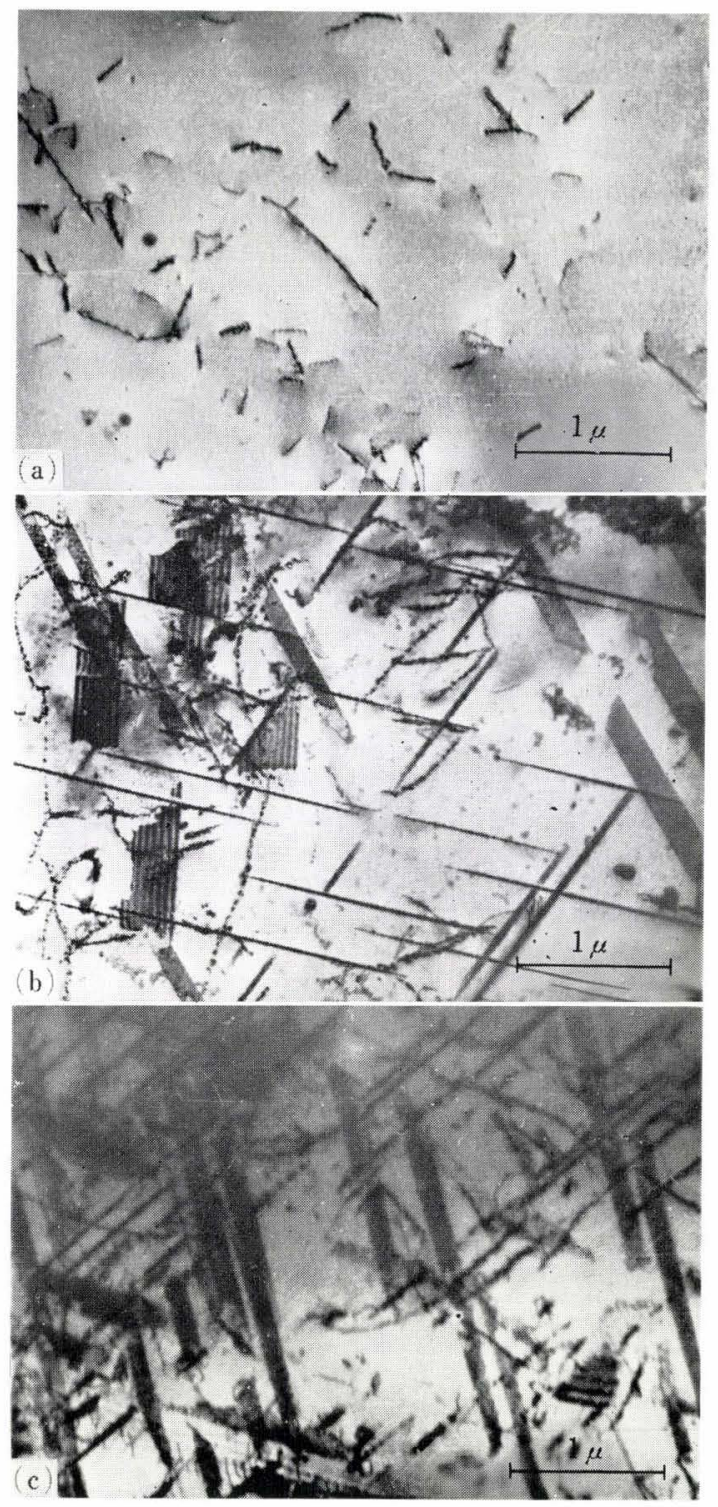

Photo. 5. Transmission electron micrographs of the solution treated specimen under creep test. Heat treatment: $1300^{\circ} \mathrm{C} \times 1 \mathrm{hr}$ W.Q. Creep test condition : $650^{\circ} \mathrm{C}, 14.0 \mathrm{~kg} / \mathrm{mm}^{2}$.
(a) after $3 \mathrm{hr}$
(b) after $100 \mathrm{hr}$
(c) after $1016.8 \mathrm{hr}$ to rupture

Photographs 6 and 7 are the transmission electron micrographs from specimens with thread and granular precipitates. In all the photographs, it is particularly noticed that dislocation entanglement with the precipitates are different according to the shape of the precipitate, though quantitative estimate is impossible. Nevertheless, it may be said that these tangles of dislocation with precipitates contribute greatly to the creep deformation. On the other hand, the transmission electron micrographs from the specimen with needle precipitates, shown in Photo. 8, are markedly different from others: apparently dislocations are entangled more with thread precipitates than with needle precipitates. Whatever the cause for this phenomenon is, it can be a factor of a great influence on the creep characteristics.

The transmission electron micrographs from extra low carbon specimen $\mathrm{C}$ are shown in Photo. 9. It will be 


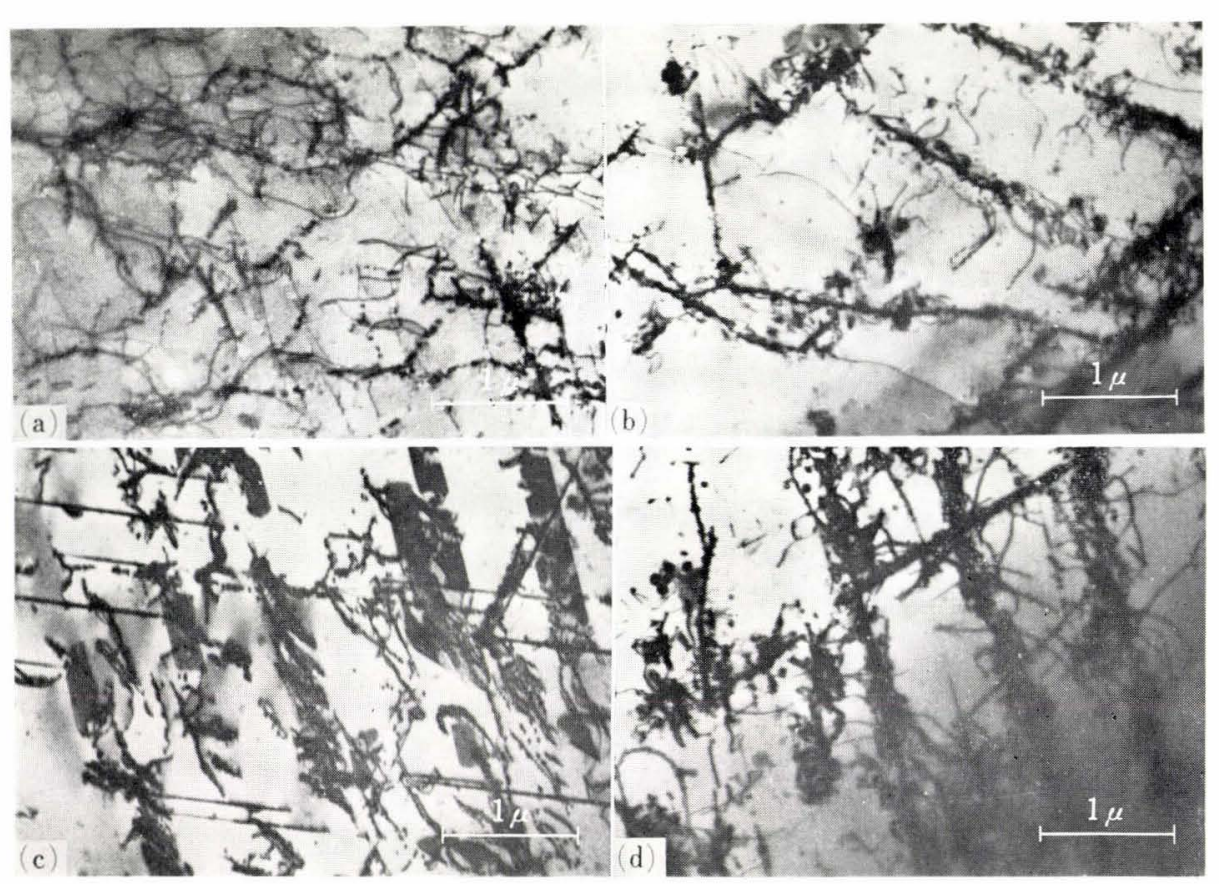

Photo. 6.

Transmission electron micrographs of specimen with thread precipitates under creep test.

Heat treatment :

(a), (b) $1300^{\circ} \mathrm{C} \times 1 \mathrm{hr}$ W.Q. $+750^{\circ} \mathrm{C}$ $\times 2 \mathrm{hr}$ W.Q.

(c), (d) $1300^{\circ} \mathrm{C} \times 1 \mathrm{hr}$ W.Q. $+800^{\circ} \mathrm{C}$ $\times 2$ hr W.Q.

Creep test condition: $650^{\circ} \mathrm{C}$, $14.0 \mathrm{~kg} / \mathrm{mm}^{2}$

(a), (c) after $3 \mathrm{hr}$

(b), (d) after $100 \mathrm{hr}$
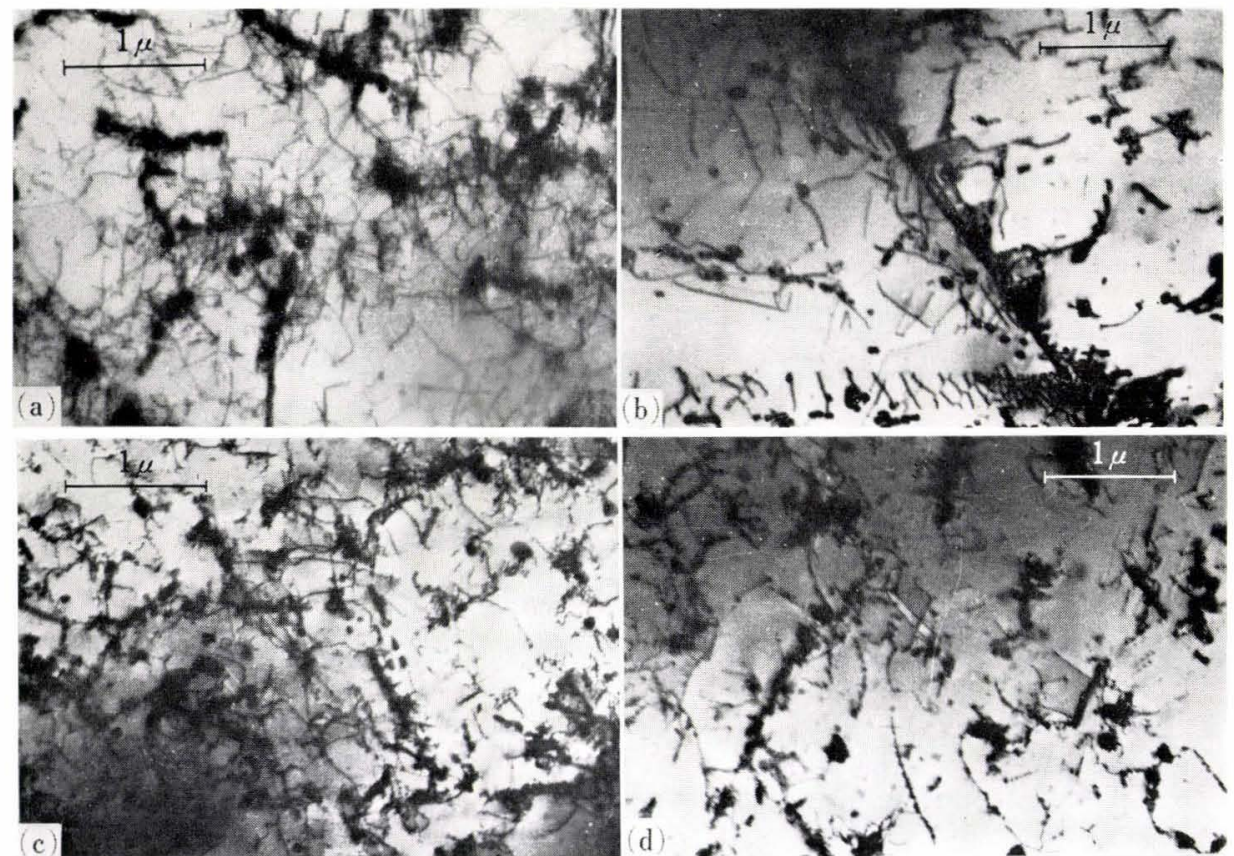

Photo. 7.

Transmission electron micrographs of specimen with granular precipitates under creep test. Heat treatment (a), (b) $1300^{\circ} \mathrm{C} \times 1 \mathrm{hr}$ W.Q.+ $1000^{\circ} \mathrm{C} \times 2 \mathrm{hr}$ W.Q. (c), (d) $1300^{\circ} \mathrm{C} \times 1 \mathrm{hr}$ W.Q. + $1100^{\circ} \mathrm{C} \times 2 \mathrm{hr}$ W.Q Greep test condition: $650^{\circ} \mathrm{C}$, $14.0 \mathrm{~kg} / \mathrm{mm}^{2}$

(a), (c) after $3 \mathrm{hr}$ (b), (d) after $100 \mathrm{hr}$

noticed that the cell structure, which was not observed in the steel $A$, was found here first. The steel $\mathrm{C}$ had the same level of soluble $\mathrm{Ti}$ content as the solution treated specimen of steel $A$ and the specimen underwent a large rupture elongation, viz., stacking faults should have developed extensively. Despite these, no stacking fault was recognized. This is taken to mean that the stacking fault energy is also dependent on the soluble G content.

\section{Room Temperature Hardness and High Temperature Tensile Properties}

To compare with the creep characteristics, hardness at room temperature and tensile properties at high temperature were tested with steel $A$ for various initial precipitation states. Vickers hardness was measured with $10 \mathrm{~kg}$ load and tensile test at high temperature was made with the specimen $(10 \phi \times 50 \mathrm{~mm}$ G. L.) at constant tensile speed (cross head speed= $1 \mathrm{~mm} / \mathrm{min}$ ). The experimental results are shown in Figs. 5 and 6 for soluble Ti content as abscissa. It will be seen in Fig. 5 that hardness decreases as the soluble Ti content increases, or, in other words, it increases with the precipitation content; this means clearly the precipitation strengthening. The age treated specimens 2 and 3 with thread precipitates had hardnesses higher by about $H_{\mathrm{V}} 20$ at the same soluble $\mathrm{Ti}$ content than the others. This may be considered at least partially to be due to the difference in the distribution of precipitates, but then the hardness difference was only a little more than the observational error. Therefore, it is concluded that the initial precipitation states do not give so much an effect on the hardness at room temperature. In the short time tensile testing, which was made 


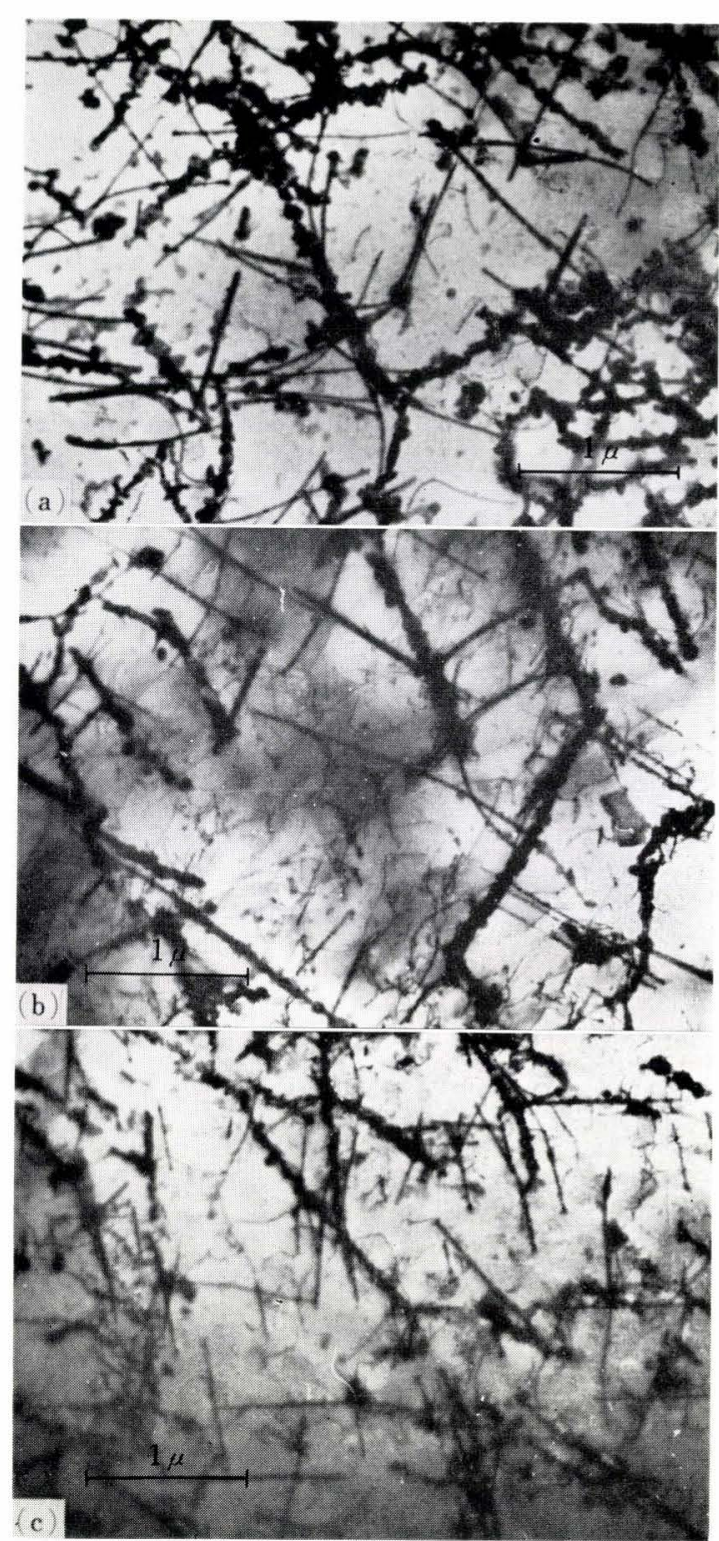

Photo. 8. Transmission electron micrographs of specimen with needle precipitates under creep test. Heat treatment: $1300^{\circ} \mathrm{C} \times 1 \mathrm{hr}$ W.Q. $+850^{\circ} \mathrm{G}$ $\times 20 \mathrm{hr}$ W.Q. Creep test condition: $650^{\circ} \mathrm{C}$, $14.0 \mathrm{~kg} / \mathrm{mm}^{2}$.
(a) after $3 \mathrm{hr}$
(b) after $100 \mathrm{hr}$
(c) after $123.6 \mathrm{hr}$ to rupture

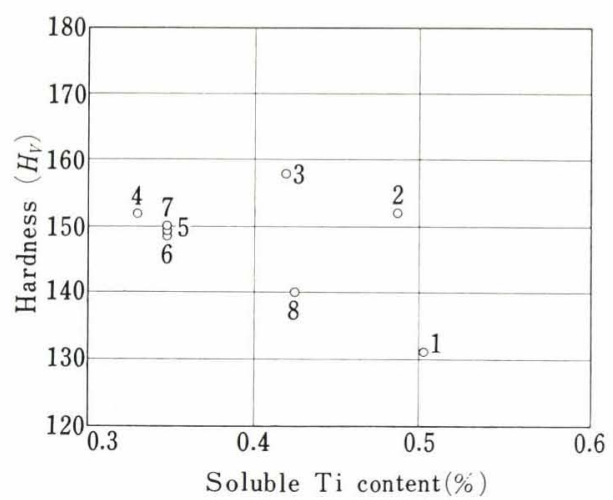

Fig. 5. Relation between hardness at room temperature and soluble Ti content

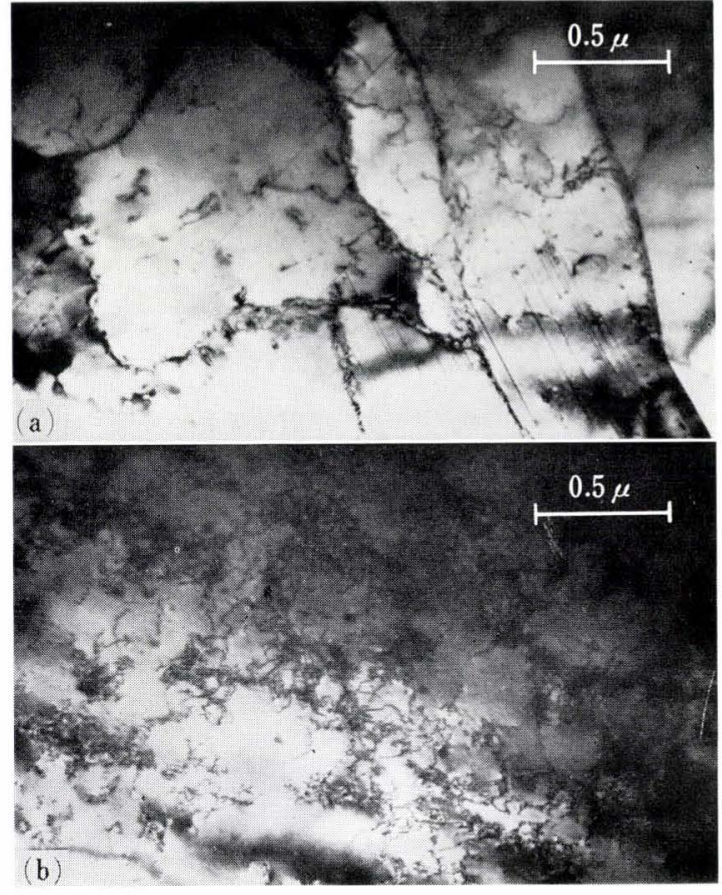

Photo. 9. Transmission electron micrographs of the steel C after creep rupture test.

Heat treatment: $1300^{\circ} \mathrm{C} \times 1 \mathrm{hr}$ W.Q. Creep test condition : $650^{\circ} \mathrm{C}, 14.0 \mathrm{~kg} / \mathrm{mm}^{2}$

under a stress higher compared to that for the creep rupture testing, tensile and yield strengths were correlated fairly well with the soluble Ti content (Fig. 6). The tensile strength increases rapidly with soluble $\mathrm{Ti}$ content; the yield strength, on the other hand, seems to decrease slightly with the soluble Ti content, except in the solution treated specimen $A-1$, where the decrease of strength was remarkable. The strength of the age treated specimens 7 and 8 with granular TiC was a little lower than the other, but it was not so much of a difference. Also, the values of elongation and reduction of area were different in each aged specimen, but its range was within $5 \%$. Therefore, it cannot be concluded that the ductility depends on the initial states. On the whole, both elongation and reduction of area seem to decrease a little with the soluble Ti content. The observation of metallurgical structures of the specimens after short time tensile testing was not very successful, because satisfactory thin foils were not obtained from the rupture parts, which inevitably contained many voids due to the grain boundary sliding. Therefore, how the shapes and distribution of precipitates influence the tensile properties at high temperature was not fully investigated. However, as these tensile properties do not depend on the initial precipitation states as mentioned above, the mutual interaction between precipitates and dislocation is believed to be small in this case.

From these results, it was confirmed that the effect of the initial precipitation states on the hardness and short time tensile properties is small as compared to that on the creep rupture characteristics, as summarized in Table 5. 
Table 5. Effect of the initial precipitation state on the properties of 18-8-Ti stainless steel

\begin{tabular}{|c|c|c|c|c|c|}
\hline \multicolumn{2}{|c|}{ Test condition } & Test method & $\begin{array}{c}\text { Characteristic } \\
\text { properties }\end{array}$ & $\begin{array}{c}\text { Property change with } \\
\text { increasing soluble } \\
\mathrm{Ti} \text { content }\end{array}$ & $\begin{array}{l}\text { *Effect of precipitate } \\
\text { state on the properties }\end{array}$ \\
\hline \multicolumn{2}{|c|}{$\begin{array}{l}\text { Room temperature } \\
\text { properties }\end{array}$} & Hardness test & Hardness & Decrease & - \\
\hline \multirow{6}{*}{$\begin{array}{l}\text { High } \\
\text { temperature } \\
\text { properties }\end{array}$} & \multirow{3}{*}{ High stress } & \multirow{3}{*}{$\begin{array}{l}\text { Short time } \\
\text { tensile test } \\
\left(650^{\circ} \mathrm{C}\right)\end{array}$} & Tensile strength & Increase & - \\
\hline & & & Yield strength & Decrease & - \\
\hline & & & Elongation & Decrease & - \\
\hline & \multirow{3}{*}{ Low stress } & \multirow{3}{*}{$\begin{array}{l}\text { Creep and } \\
\text { creep rupture } \\
\text { test }\left(650^{\circ} \mathrm{C}\right)\end{array}$} & Initial strain & Increase & - \\
\hline & & & Min. creep rate & Decrease & + \\
\hline & & & Creep rupture time & Increase & + \\
\hline
\end{tabular}

* + means that the effect of initial precipitate states (precipitate morphology) on the properties is clearly recognized. - means that its effect is not recognized.
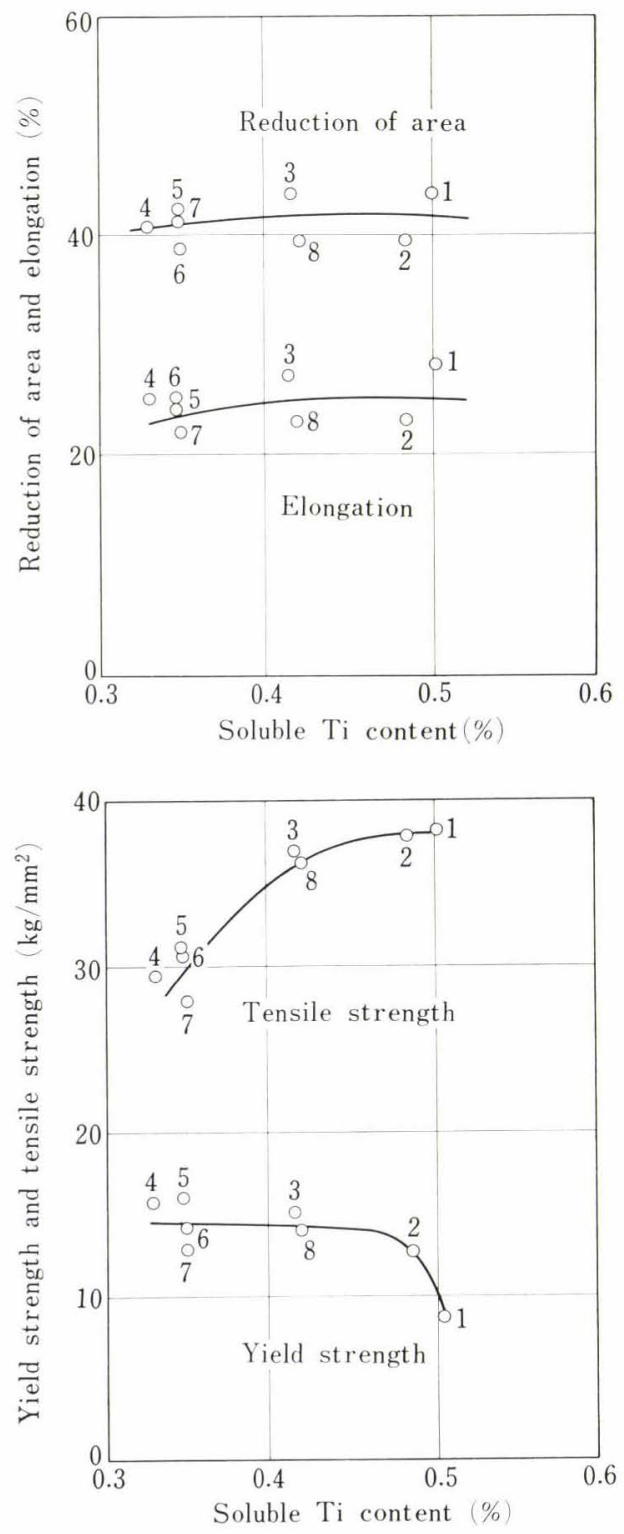

Fig. 6. Relation between mechanical properties at $650^{\circ} \mathrm{C}$ and soluble Ti content

\section{Discussion}

The results of the present study show that the creep rupture characteristics can be represented fairly well as a function of soluble $\mathrm{Ti}$ (or soluble $\mathrm{C}$ ) content and that the effect of precipitates is additive to it. The thread precipitate has a larger effect on the creep strength than the granular precipitate, but the needle precipitate decreases the creep strength markedly. From the metallurgical observations of the specimens after creep testing, it was seen that dislocations were entangled with granular and thread precipitates, but mutual interaction between dislocation and needle precipitate was not found. These phenomena are discussed from the viewpoint of solution and precipitation strengthening.

In influencing the creep rate, the effect of soluble element through the recovery rate is generally believed to be much larger than that by the strain hardening. For the effects of soluble element on recovery rate, three basic mechanisms are considered possible ${ }^{8)}$

(1) One is the effect that is due to the difference in the atomic radii, resulting in the soluble element inhibiting jog formation, hence easy climb of dislocation.

(2) The soluble element that is attracted to stacking fault enlarges its width, making the climb of dislocation and cross slip more difficult.

(3) When quantitatively large amount of soluble element is present, the diffusion velocity is changed, and so is the creep rate.

In this experiment, the soluble $\mathrm{Ti}$ content is small and the atomic radius is not so much different from that of the matrix; therefore, items (1) and (3) are negligible. The results of metallography show, on the other hand, that the appearance of stacking fault is largely dependent on the content of soluble $\mathrm{Ti}$ and soluble $\mathrm{C}$. Therefore, among the effects of soluble element, the effect on the stacking fault energy of item (2) is considered to be most important.

However, the soluble $\mathrm{Ti}$ contributes only a little to the creep rupture strength, as seen in steels $B, C$, and $D$ with extra low carbon. The creep rupture time of 
solution treated $18-8$ steel, which has $0.05 \% \mathrm{C}$ but no $\mathrm{Ti}$, is reported to be about $100 \mathrm{hr}$ at $650^{\circ} \mathrm{C}$ with $14.0 \mathrm{~kg} /$ $\mathrm{mm}^{2}$ stress. $^{9)}$ From these results, it may be concluded that the effect of soluble $\mathrm{C}$ and $\mathrm{Ti}$ only on the creep rupture strength is not so large. Also, the strengthening in the solution treated specimen $A-1$ is thought almost attributable to the solute elements $\mathrm{Ti}$ and $\mathrm{C}$, but cannot be explained by the additive effect of soluble $\mathrm{Ti}$ and $\mathrm{C}$ alone from the above description. Accordingly, the mutual interaction by coexistence of soluble $\mathrm{Ti}$ and soluble $\mathrm{C}$ is considered to be fairly large for the strengthening. The content of soluble $\mathrm{C}$ calculated assuming the precipitated $\mathrm{Ti}$ is in $\mathrm{Ti}_{2} \mathrm{~S}$, $\mathrm{TiN}$, and $\mathrm{TiC}$ is shown in the abscissa of Fig. 6. Ti and $\mathrm{C}$ are dissolved in steel A to a considerable extent.

For the creep rupture strength the precipitation effect is additive to the solution strengthening, where the former is by acting as obstacle for dislocation movement, which is revealed in the form of dislocation tangle with precipitate in the metallurgical observation. Furthermore, even if the difference of creep rupture strength by precipitate shapes, granular or thread, can be explained qualitatively by the difference of mutual potential barrier, the quantitative estimation is difficult. In the aged specimens $A-4$ and $A-6$, on the other hand, the tangle of dislocation with needle precipitate was not observed. This means that the needle precipitate offers no resistance for the creep deformation, but this does not necessarily mean that the creep rupture strength suffers a great decrease. To explain the remarkable strength decrease that was actually observed, the precipitation of needle carbides itself should have an effect of accelerating the decrease of creep rupture strength, for which it is necessary to examine other factors.

For example, there is the interaction between $\mathrm{Ti}$ and G, both as solute elements. Namely, the soluble C content in the age treated steels $A-4$ and $A-6$ decreases readily with the precipitation of TiC. Now, suppose that the needle precipitate is actually $\mathrm{Cr}_{3} \mathrm{C}_{2}$ as discussed earlier, the soluble $\mathrm{C}$ content will decrease further with the precipitation of this needle carbide. When the soluble $\mathrm{C}$ content becomes lower than a certain threshold value, the effective mutual interaction between soluble $\mathrm{Ti}$ and soluble $\mathrm{C}$ for the solution strengthening vanishes, whereby the creep rupture strength decreases. However, more detailed investigation is necessary to obtain conclusive evidence.

\section{Summary}

(1) The creep and creep rupture characteristics were shown to be well correlated to soluble Ti (or soluble C) content. In this case, not only the soluble Ti but also the soluble $\mathrm{C}$ content plays an important role for the stacking fault formation, and the mutual interaction arising from the co-existence of soluble $\mathrm{Ti}$ and $\mathrm{C}$ is considered to be very effective on the creep strength.

(2) Moreover, it was clearly recognized that the creep strength is influenced greatly by the initial precipitation states. This was discussed from the viewpoint of the mutual interaction, i.e. tangle of dislocation with precipitates, which is very different according to the initial precipitation states.

(3) The needle precipitate was assumed to be $\mathrm{Cr}_{3} \mathrm{C}_{2}$, and it was found that $\mathrm{Cr}_{3} \mathrm{C}_{2}$ is closely related with the great decrease of the creep rupture strength. Its cause was also discussed.

(4) It was ascertained that the initial precipitation states are less effective on hardness and short time tensile properties in comparison with the creep rupture characteristics.

\section{Acknowledgements}

The author wishes to thank Dr. M. Sumitomo, the Director of the Central Research Lab. of Sumitomo Metal Ind., Ltd., for permission to publish the results, and Dr.. E. Miyoshi, of the same Institute, for guidance in his research. Thanks are also due to Mr. T. Abe and Mr. M. Kashihara for their cooperation.

\section{REFERENCES}

1) G. S. Ansell and J. Weertman: Trans. AIME, 215 (1959), 838.

2) D. Mclean: Mechanical Properties of Metals, (1962), 32, John Wiley \& Sons Inc., New York.

3) E. Miyoshi : J. Japan Inst. Metals, 28 (1964), 604.

4) E. Miyoshi and T. Yukitoshi : Iron and Steel, 53 (1967), 570.

5) E. Miyoshi and T. Yukitoshi: Sumitomo Metals, 19 (1967), 67.

6) E. Miyoshi : J. Japan Inst. Metals, 25 (1961), 581.

7) F. Garofals: Fundamentals of Creep and Creep Rupture in Metals, (1965), 142, The Macmillan Company, New York.

8) H.J. Harding and R. W. K. Honeycombe: J. Iron Steel Inst., 204 (1966), 259.

9) Sumitomo Metal Ind., Ltd. : “High Temperature Characteristics of Steels for Boiler Tubes," (1962), Japan. 